RESEARCH REPORT

\title{
Roads, railways, and childhood cancers
}

\section{E G Knox}

\begin{abstract}
Study objectives: To locate geographical sources of engine exhaust emissions in Great Britain and to link them with the birth addresses of children dying from cancer. To estimate the cancer initiating roles of nearby roads and railways and to measure effective ranges.

Design: Birth and death addresses of all children born between 1955 and 1980 in Great Britain, and dying from leukaemia or other cancer during those years, were linked to locations of railway stations, bus stations, ferry terminals, railways, roads, canals, and rivers. Nearest distances to births and deaths were measured, and migration data relating to children who had moved house were analysed. Excesses of close to hazard birth addresses, compared with close to hazard death addresses, indicate a high prenatal or early postnatal risk of cancer initiation.

Setting and subjects: Child cancer birth and death addresses and their map references were extracted from an earlier inquiry. Map references of putative hazards were downloaded from the Ordnance Survey national digital map of Great Britain. These data are recorded to a precision of one metre and have ground accuracies around 20 metres.

Main results: Significant birth excesses were found within short distances of bus stations, railway stations, ferries, railways, and $A, B$ class roads, with a relative risk of 2.1 within $100 \mathrm{~m}$, tapering to neutral after $3.0 \mathrm{~km}$. About $24 \%$ of child cancers were attributable to these joint birth proximities. Roads exerted the major effect.

Conclusions: Child cancer initiations are strongly determined by prenatal or early postnatal exposures to engine exhaust gases, probably through maternal inhalation and accumulation of carcinogens over many months. The main active substance is probably 1,3-butadiene.
\end{abstract}

See end of article for authors' affiliations ......................

Correspondence to: Professor E G Knox, Mill Cottage, Front Street, Great Comberton, Pershore, Worcestershire WR10 3DU, UK; E.G. Knox@btinternet.com

Accepted for publication 8 October 2005
$\mathrm{P}$ revious studies showed that many childhood cancers are initiated during fetal life or early infancy through exposure to atmospheric carcinogens. Places of birth were associated with industrial sources of oil combustion products, volatile fuels, and solvents: and with high local emissions of specific chemicals associated with oil fuels. ${ }^{1-3}$ Four such substances (1,3-butadiene, benzene, benzo(a)pyrene, dioxins) are known carcinogens and the first two are derived largely from fuelling and operating internal combustion engines (ICEs). Distributions of all the emissions and sources were geographically confounded with each other but a combined analysis showed the cancer births to be especially associated with 1,3-butadiene, with installations using heavy rail or road transport, with railway lines, and with bus/coach stations. ${ }^{45}$ The bus stations showed an extraordinary relative risk (RR) of 12.1 within $0.3 \mathrm{~km}$. Together with other diesel associations, this showed a specific association with exhaust gases rather than with volatile fuel evaporation. All these effects were evident at the shortest measurable ranges, as expected from ground level discharges, but the coarse resolution of available "emissions hotspots" maps created uncertainties. ${ }^{67}$ The railway data, obtained through manual digitisation, were also inadequate for taking the matter to higher resolutions; and detailed road data-necessary for any comprehensive ICE related examination-were not then available.

This study tackles these limitations by extracting exact road, rail, and other data from the national digital mapping archive held by the Ordnance Survey (OS) and by re-examining the ICE exhaust hypothesis on a fine geographical scale.

\section{METHODS}

The cancer cases analysed here are those described in a previous report: all children who died between 1955 and 1980 in Great Britain before their 16th birthdays and who had been born in the same period. ${ }^{8}$ Postcodes (PCs) of their home addresses at birth and at death were converted to map references through the Central PC Directory. Less reliable addresses and map references were excluded. The resulting database consisted of 12017 children.

Urban PC map references represent actual addresses within 100-200 m with a mean error of 50-100 m. Rural PCs are generally larger and the probable errors are not definable. The cancers were originally classified into 10 diagnostic subtypes but earlier studies showed similar geographical proximity relations for each cancer subtype, as well as for two main groups: the reticuloendothelial cancers (leukaemias and lymphomas), and the other "solid" tumours. These main groups were re-examined here, confirming their similarity. Apart from this, the main results shown below relate to all cancers/leukaemias together.

Coordinates of mapped hazards were obtained from a subset of the OS national digital mapping archive, through the "Digimap" facility hosted by Edinburgh University. ${ }^{9}$ Of the several digital files, the subset "strategi" proved to be the most suitable. Its content is limited, corresponding roughly to that of the 1:200 000 OS motoring atlas, but the recorded features are specified to a precision of 1 metre. Unlike the higher resolution files, it is conveniently downloadable in only two large "tiles", north and south of $400 \mathrm{~N}$. It includes motorways, A class roads (single and dual), B class roads ( single and dual), minor roads ( $>4 \mathrm{~m}$ wide and $<4 \mathrm{~m}$ wide), canals, rivers, railways, and railway stations. Point features are given as single coordinate pairs and linear features as separated sets of coordinates representing "vertices", with

Abbreviations: RR, relative risk; ICE, internal combustion engine; $O S$, Ordnance Survey 
assumed linear interpolations. Details are presented in the appendix.

Lists of hazard coordinates were scanned against all addresses for points of nearest approach. Where appropriate, perpendiculars were dropped to lines connecting vertices. In practice, the vertices were so tightly set that this made little difference to the results of initial essays using the vertices alone. Railway stations were additionally inspected using the OS online "get-a-map" facility to estimate the compass bearing (to 5 degrees, using a protractor against the computer screen map) of the track passing through the station. In addition to the station, with idling diesel locomotives, this permitted calculation of risk estimates around the fume rich acceleration zones on either side. Perpendiculars were dropped to varied line extensions $(0.2,0.4,0.6,0.8$, and $1.0 \mathrm{~km})$; and, for comparison, this was repeated transversely to the track. Underground stations, tramways, tramway connections, and recently built stations were omitted. The latter were ascertained through reference to a 1992 railway atlas. ${ }^{10}$

Bus and coach stations were identified from national timetables and located visually on OS maps to a precision of $0.1 \mathrm{~km}$. Those marked by symbols on OS maps, mainly town centre stations, were listed and tested separately.

Vehicle ferry terminals, civil airports, and holiday resorts, were added to the lists of point features using similar visual methods, for purposes to be described later.

$\mathrm{RR}$ at different distances from the nearest hazard points were estimated among children who moved house. For short distances the short range birth-death ratio serves as an estimator of RR. Its validity depends upon the premise of a short term migration equilibrium between different areas among the general child population. Against such a background, with an expectation of equal outward and inward movements relative to any nominated point, an excess of short range birth addresses represents a cancer hazard selection. Absolute numbers of cancer initiations attributable to hazard proximities are estimated as the difference between numbers of nearby births and nearby deaths.

Estimates of RR based on birth/death ratios can be sharpened by restricting them to children crossing a specific circumferential boundary around a point hazard (or lines parallel to a linear feature). This procedure excludes those children who migrated entirely within (or between) near field or far field locations or over very short radial distances. Ratios between such outward and inward movements are characterised below as "traverse limited". These approaches are illustrated in the last two columns of tables 1 and 2 .

An elaborated version of the boundary crossing technique, especially useful for examining simultaneous exposures to several hazard types, designates multiple lines at 50 metre intervals around the hazards, providing a contour map of exposure intensities. It permits synthesis of a sequence of different traverses. This is a comparatively efficient approach, retrieving additional information, and results from its application are shown below (for example, in table 3).

\section{RESULTS}

The 12017 reliably located post-1954 birth and death records included 5663 children who moved house by more than $0.5 \mathrm{~km}$. The primary analyses are based upon this group and table 1 distributes the 5663 births and deaths according to their distances from individual map features. The last two columns give cumulative values corresponding with the first three $(0.0-0.3 \mathrm{~km})$ and the first four columns $(0.0-0.5 \mathrm{~km})$, but restricted to those who traversed these limiting boundaries in either direction. Table 2 shows results obtained by combining pairs or larger groups of features, or by separating overlapping relations. These tabulations were repeated separately for the 2806 reticuloendothelial and the 2857 "solid" cancers. The results were indistinguishable and subsequent findings refer to the combined set.

\section{Bus/coach stations}

These results confirmed the high RRs already shown around 455 bus stations located in national timetables. ${ }^{5} \mathrm{RR}$ within $0.5 \mathrm{~km}$ was 5.79 . The excess risk tapered as far as $1.0 \mathrm{~km}$, accumulating an attributable set of 479 additional cancer births (8.5\% of 5663). Bus stations marked on OS maps (302), mainly in busy city centre sites, accounted for 375 excess cancers and the traverse limited RRs were 8.28 within $0.3 \mathrm{~km}$ and 7.12 within $0.5 \mathrm{~km}$. Non-OS bus terminals showed weaker RRs (3.42 and 3.15) but still contributed substantially with 105 extra cancer births: 1.9\% of migrants.

A similar analysis was performed for approach roads or waiting areas at vehicle ferry terminals, including those with foreign destinations and those crossing estuaries and sea passages within this country. There were few births within $1.0 \mathrm{~km}$ of these sites but there was a birth/death ratio of $82 /$ 41 (2.00) within $2.0 \mathrm{~km}$ and 168/108 (1.56) within $3.0 \mathrm{~km}$.

\section{Railway stations}

Railway stations showed a similar tapering pattern with RRs of $2.11(\mathrm{CI}=1.76$ to 2.53$)$ and $2.44(2.16$ to 2.76$)$ at 0.3 and $0.5 \mathrm{~km}$ and lesser excesses as far as $1.0 \mathrm{~km}$. This was less than for bus stations, but more children were involved and the 842 birth excesses within $1.0 \mathrm{~km}$ exceeded those for bus stations or ferry points, representing $14.9 \%$ of the 5663 migrants. Major bus stations are often adjacent to railway stations and their associated birth distance distributions are far from independent so a joint list of both features was examined (section 1: table 2). It showed an excess of 869 cases within $1.0 \mathrm{~km}$ of either: raising jointly attributable cancers to $15.3 \%$ of all migrants.

\section{Departure track extensions}

Railway station through-tracks were extended each way in steps of $0.2 \mathrm{~km}$ up to $1.0 \mathrm{~km}$ along their compass bearings. Birth/death ratios within $0.3 \mathrm{~km}$ of these extensions increased from an initial 1.74 (347/199) for no extension to 1.93 for the $0.4 \mathrm{~km}$ extension (882/457); but then decreased (section 2 of table 2). Numbers of attributable cancers increased from an initial 148 to 425 at $0.4 \mathrm{~km}$ and decreased thereafter.

The stations were extended similarly along an imaginary line drawn at right angles to the track. Surprisingly, the rise and fall patterns were similar and there were even more attributable cases for the $0.4 \mathrm{~km}$ extension (477) than for the tangential one. This presumably results from adjacent hazards such as bus stations, bus stops, road traffic, car parks, shopping areas, and other commercial and industrial activities. It will require other evidence to show how much is attributable to the railways and the locomotives themselves.

\section{Railway lines}

Birth/death excesses here were concentrated within $0.5 \mathrm{~km}$ and (including stations) showed a ratio of 2457/1707 (1.44:1.34 to 1.54 ). The excess of 750 amounted to $13.2 \%$ of all migrants. Railway lines remote from the extended station tracks were examined separately. Results for near points where there was no station closer than $0.5 \mathrm{~km}$ are shown in section 3 of table 2 . The RRs at 0.3 and $0.5 \mathrm{~km}$ were only 1.12 and 1.20 but the respective cancer excesses were 60 and 
Table 1 Shortest distances from births and deaths to selected map features

\begin{tabular}{|c|c|c|c|c|c|c|c|c|}
\hline & \multicolumn{8}{|c|}{ Distances (km) } \\
\hline & -0.1 & -0.2 & -0.3 & -0.5 & -1.0 & $>1.0$ & $0-0.3^{*}$ & $0-0.5^{*}$ \\
\hline \multicolumn{9}{|c|}{ 1. Bus stations } \\
\hline Births & 12 & 113 & 92 & 224 & 374 & 4848 & 215 & 423 \\
\hline Deaths & 3 & 14 & 18 & 52 & 249 & 5327 & 33 & 73 \\
\hline$B / D$ ratio & 4.00 & 8.07 & 5.11 & 4.31 & 1.50 & 0.91 & 6.52 & 5.79 \\
\hline \multicolumn{9}{|c|}{ 2. Railway stations } \\
\hline Births & 23 & 113 & 261 & 656 & 1350 & 3260 & 376 & 926 \\
\hline Deaths & 23 & 65 & 111 & 308 & 1054 & 4102 & 178 & 380 \\
\hline$B / D$ ratio & 1.00 & 1.74 & 2.35 & 2.12 & 1.28 & 0.79 & 2.11 & 2.44 \\
\hline \multicolumn{9}{|l|}{ 3. Railways } \\
\hline Births & 257 & 490 & 476 & 1058 & 1316 & 2066 & 974 & 1509 \\
\hline Deaths & 175 & 350 & 376 & 685 & 1443 & 2634 & 652 & 814 \\
\hline$B / D$ ratio & 1.47 & 1.40 & 1.27 & 1.54 & 0.91 & 0.78 & 1.49 & 1.85 \\
\hline \multicolumn{9}{|l|}{ 4. Motorways } \\
\hline Births & 9 & 18 & 17 & 61 & 290 & 5268 & 37 & 88 \\
\hline Deaths & 6 & 18 & 33 & 97 & 284 & 5225 & 50 & 137 \\
\hline$B / D$ ratio & 1.50 & 1.00 & 0.52 & 0.63 & 1.02 & 1.01 & 0.74 & 0.64 \\
\hline \multicolumn{9}{|l|}{ 5. A roads } \\
\hline Births & 713 & 862 & 640 & 699 & 1142 & 1607 & 1533 & 1536 \\
\hline Deaths & 336 & 627 & 519 & 831 & 1296 & 2054 & 800 & 936 \\
\hline$B / D$ ratio & 2.12 & 1.37 & 1.23 & 0.84 & 0.88 & 0.78 & 1.92 & 1.64 \\
\hline \multicolumn{9}{|l|}{ 6. B roads } \\
\hline Births & 509 & 579 & 513 & 704 & 1130 & 2228 & 1148 & 1322 \\
\hline Deaths & 289 & 531 & 424 & 716 & 1251 & 2452 & 791 & 977 \\
\hline$B / D$ ratio & 1.76 & 1.09 & 1.21 & 0.98 & 0.90 & 0.91 & 1.45 & 1.35 \\
\hline \multicolumn{9}{|c|}{ 7. Minor roads $>4 \mathrm{~m}$ wide } \\
\hline Births & 846 & 1027 & 819 & 915 & 754 & 1302 & 1144 & 806 \\
\hline Deaths & 726 & 1165 & 886 & 1044 & 850 & 992 & 1231 & 1018 \\
\hline$B / D$ ratio & 1.17 & 0.88 & 0.92 & 0.88 & 0.89 & 1.31 & 0.93 & 0.79 \\
\hline \multicolumn{9}{|c|}{ 8. Minor roads $<4 \mathrm{~m}$ wide } \\
\hline Births & 135 & 162 & 154 & 283 & 632 & 4297 & 332 & 472 \\
\hline Deaths & 146 & 219 & 168 & 328 & 807 & 3995 & 414 & 599 \\
\hline$B / D$ ratio & 0.92 & 0.74 & 0.92 & 0.86 & 0.78 & 1.08 & 0.80 & 0.79 \\
\hline \multicolumn{9}{|l|}{ 9. Canals } \\
\hline Births & 58 & 64 & 79 & 166 & 466 & 4830 & 176 & 301 \\
\hline Deaths & 28 & 49 & 73 & 154 & 339 & 5020 & 125 & 237 \\
\hline $\mathrm{B} / \mathrm{D}$ ratio & 2.07 & 1.31 & 1.08 & 1.08 & 1.37 & 0.96 & 1.41 & 1.27 \\
\hline \multicolumn{9}{|l|}{ 10. Estuaries } \\
\hline Births & 9 & 14 & 18 & 69 & 204 & 5349 & 38 & 98 \\
\hline Deaths & 4 & 16 & 13 & 47 & 141 & 5442 & 30 & 68 \\
\hline$B / D$ ratio & 2.25 & 0.88 & 1.38 & 1.47 & 1.45 & 0.98 & 1.27 & 1.44 \\
\hline \multicolumn{9}{|c|}{ 11. Other rivers } \\
\hline Births & 172 & 287 & 370 & 812 & 1393 & 2629 & 663 & 1051 \\
\hline Deaths & 169 & 286 & 355 & 747 & 1587 & 2519 & 644 & 968 \\
\hline$B / D$ ratio & 1.02 & 1.00 & 1.04 & 1.09 & 0.88 & 1.04 & 0.98 & 1.09 \\
\hline
\end{tabular}

Table 2 Combinations and separations

\begin{tabular}{|c|c|c|c|c|c|c|c|c|}
\hline & \multicolumn{8}{|c|}{ Distances (km) } \\
\hline & -0.1 & -0.2 & -0.3 & -0.5 & -1.0 & $>1.0$ & $0-0.3^{*}$ & $0-0.5^{*}$ \\
\hline \multicolumn{9}{|c|}{ 1. Bus and railway stations combined } \\
\hline Births & 30 & 217 & 307 & 685 & 1289 & 3135 & 558 & 1117 \\
\hline Deaths & 23 & 74 & 120 & 329 & 1113 & 4004 & 200 & 402 \\
\hline$B / D$ ratio & 1.30 & 2.93 & 2.56 & 2.08 & 1.16 & 0.78 & 2.79 & 2.78 \\
\hline \multicolumn{9}{|c|}{ 2. Rail acceleration tracks: $\pm 0.4 \mathrm{~km}$} \\
\hline Births & 253 & 259 & 371 & 644 & 1243 & 2893 & 1153 & 1552 \\
\hline Deaths & 126 & 148 & 183 & 435 & 1090 & 3681 & 676 & 802 \\
\hline$B / D$ ratio & 2.01 & 1.75 & 2.03 & 1.48 & 1.14 & 0.79 & 1.71 & 1.94 \\
\hline \multicolumn{9}{|c|}{ 3. Railways excluding acceleration tracks } \\
\hline Births & 134 & 276 & 256 & 578 & 837 & 3582 & 581 & 971 \\
\hline Deaths & 113 & 228 & 265 & 467 & 1063 & 3527 & 521 & 806 \\
\hline$B / D$ ratio & 1.19 & 1.21 & 0.97 & 1.24 & 0.79 & 1.02 & 1.12 & 1.20 \\
\hline \multicolumn{9}{|c|}{ 4. Bus stations, rail acceleration tracks, and other railways } \\
\hline Births & 444 & 594 & 573 & 960 & 1204 & 1888 & 1012 & 1626 \\
\hline Deaths & 254 & 380 & 401 & 711 & 1472 & 2445 & 499 & 800 \\
\hline$B / D$ ratio & 1.75 & 1.56 & 1.43 & 1.35 & 0.82 & 0.77 & 2.03 & 2.03 \\
\hline \multicolumn{9}{|c|}{ 5. A roads and B roads combined } \\
\hline Births & 1137 & 1246 & 832 & 890 & 949 & 609 & 1774 & 1419 \\
\hline Deaths & 592 & 1059 & 779 & 1129 & 1223 & 881 & 989 & 874 \\
\hline$B / D$ ratio & 1.92 & 1.18 & 1.07 & 0.79 & 0.78 & 0.69 & 1.79 & 1.62 \\
\hline
\end{tabular}


Table 3 Migration polarities near roads, railways, bus/rail stations, ferries. Banded according to distance from nearest address

\begin{tabular}{llllll}
\hline Nearest* distance $(\mathbf{k m})$ & Birth nearest & Death nearest & Excess births & B/D ratio & $95 \%$ Cl \\
\hline-0.1 & 1442 & 703 & 739 & 2.05 & 1.87 to 2.24 \\
-0.2 & 1001 & 683 & 318 & 1.48 & 1.33 to 1.62 \\
-0.3 & 485 & 332 & 153 & 1.46 & 1.27 to 1.69 \\
-1.0 & 249 & 123 & 126 & 2.02 & 1.63 to 2.51 \\
-3.0 & 191 & 161 & 30 & 1.19 & 0.96 to 1.46 \\
Total & 3368 & 2002 & 1366 & 1.68 & 1.59 to 1.78 \\
B/D ratio within $0.3 \mathrm{~km}=1.70$ & & & & \\
Attributable percentage within $3.0 \mathrm{~km}=24.1$ & & & & \\
Attributable percentage within $0.3 \mathrm{~km}=21.3$ & & & &
\end{tabular}

*These are upper limits of distance bands synthesised from $50 \mathrm{~m}$ search bands within the effective ranges of the included hazards. Polarities are determined for children migrating across successive $50 \mathrm{~m}$ boundaries up to a maximum of $3.0 \mathrm{~km}$.

165, showing some evidence of a railway proximity effect beyond the reach of the station-related acceleration and transverse zones.

\section{Roads}

A roads, B roads, minor roads $>4 \mathrm{~m}$ wide, and minor roads $<4 \mathrm{~m}$ wide, displayed reducing birth/death ratios with diminishing traffic-class and with increasing distance. The respective $0.3 \mathrm{~km}$ traverse limited RRs for the four classes of road were 1.92 ( 1.75 to 2.10 ), 1.45 ( 1.32 to 1.60 ), 0.93 and 0.80 . Urban streets are not recorded here so most minor roads, and locations distant from the A,B roads, represent rural areas. There was an excess of 785 births within $0.3 \mathrm{~km}$ of $\mathrm{A}, \mathrm{B}$ roads together, amounting to $13.9 \%$ of all migrant cancers. Rural birth locations, represented by the minor roads, were strongly "protective". There were no birth excesses near motorways; indeed, very few addresses of any kind. Many motorways did not exist at that time and their current locations often represent low population rural areas.

\section{Waterways}

Canals displayed few nearby addresses and the weak relation with cancer births is probably attributable to adjacent features rather than canal traffic. Lower reaches of main rivers, shown in table 1 as "estuaries", and coded to the centre of the waterway, showed few nearby addresses and no clear cancer initiating effects. Other river classes, taken together, showed nothing.

\section{Locomotive effects}

Many rail lines in south east England have for many years used third rail electrification (750 V DC) although this did not reach the coastal towns until about 1970. Proximity studies were performed separately for hazards east of $480.0 \mathrm{E}$ and south of $175.0 \mathrm{~N}$ (a useful defining point near Reading). Railway station acceleration tracks here showed birth/death asymmetries of only 113/96(1.36) at $0.3 \mathrm{~km}$ compared with

\section{What this paper adds}

It elaborates previous findings of a link between internal combustion engine fuelling/operating and births of children later developing cancer/leukaemia. Shows further evidence that the link is through exhaust gases and that 1,3-butadiene is the most probable causal agent. Establishes short $10.1-$ $0.5 \mathrm{~km}$ ) effective ranges and shows that over $24 \%$ of child cancers are thus initiated. Infers probable occurrence of "biological magnification" with mothers accumulating and concentrating carcinogens over extended periods.
$752 / 361(2.08)$ elsewhere $(p<0.01)$. The difference suggests a direct locomotive effect.

\section{Times and places}

Ratios between "near" and "far" birth addresses relative to different hazards, were examined in different years and in different seasons. A first study sought secular changes in near rail $\mathrm{B} / \mathrm{D}$ ratios that might be related to the introduction of diesel locomotives. There were irregularities, some years showing unexplained excesses or deficits over adjacent years, but there was nothing that clearly corresponded with known equipment changes or strikes or other rail stoppages. The railway system underwent major changes after the "modernisation plan" of 1956, and a major retrenchment after the Beeching economic review in 1963, and cancer death sequences themselves were affected by improving survival. An intrinsic "rail diesel effect", if it existed, failed to show through these complexities.

A second study sought seasonal road related proximity changes in places with high summer holiday traffic, including the ferries mentioned above, civil airports, and a list of traffic-notorious holiday resorts. "Surrounding zones" were defined within various radii $(5.0 \mathrm{~km}, 10.0 \mathrm{~km})$ and seasonal near-road B/D ratios inside these zones were compared with the same ratios outside. Rail proximity effects were likewise examined. No local seasonal near/far variations were found.

\section{Combined effects}

Aggregation of birth and death distributions around combined map features, as in table 2, raised problems. There was double counting in some combinations, while differing effective ranges could result in conflicting migration polarities, and it was difficult to show the marginal effects of one hazard over another. It was here that an examination of successive exposure contours proved useful. Distance contours were set at $50 \mathrm{~m}$ intervals around the component hazards, within their individual effective ranges. For each child the contour intervals were scanned from nearest to farthest, examining all the listed hazards within each exposure band before proceeding to the next band. The

\section{Policy implications}

There is an urgent need to monitor and control ICE exhaust emissions, especially with respect to 1,3-butadiene. The controls need to be comprehensive covering road, rail, and marine sources and possibly oil fired space heating systems and furnaces. The controls should be directed specifically towards emissions from known sources. 


\section{Key points}

Childhood cancer birthplaces are strongly and closely associated with $A$ and $B$ class roads, railways, bus/coach stations, railway stations, vehicle ferry ports, and the commercial and industrial environments surrounding these features. The effects are evident at ranges down to 100 metres, decaying rapidly with increasing distance, and the relevant pollutants are evidently discharged at low level. This, and the close range potency of vehicles not using volatile fuels (for example, diesel buses), shows that the main carcinogens are associated with engine exhausts. The chief carcinogenic agent is probably 1,3-butadiene and it is probably inhaled and accumulated by the mother over a prolonged period. It probably accounts for most childhood cancer initiations although the clinical onsets of leukaemia, in particular, may sometimes be precipitated by an infection.

polarity of the first detected boundary traverse was accepted and the search terminated. This excluded double counting of individual children and eliminated conflicts between opposite-polarity traverses. This procedure uses short migrations crossing steep local risk-gradients, exploiting the high precision of the map data, and it retrieves information lost in the simpler method.

This approach was used to search successive $0.05 \mathrm{~km}$ bands within $0.3 \mathrm{~km}$ of $\mathrm{A}$ and $\mathrm{B}$ roads, of railways, and of combined roads and railways. The respective outward/inward ratios were $2543 / 1539(R R=1.65), 1079 / 747(R R=1.44)$, and $2753 / 1733(\mathrm{RR}=1.79)$. Attributable percentages were 17.7(roads), 5.9(railways), and 18.0(joint). The road and rail RRs (at $0.3 \mathrm{~km}$ ) were similar to those in tables 2 and 3 but road-proximity attributable risks increased. Differences between the combined and individual hazards showed that roads-exerted the major effect. Re-ordering the rail/road components of the combined analysis made no material difference. A similar analysis post-1968, excluding the electrified south east region, gave similar results.

Table 3 displays a combined analysis of railways, railway stations, tangential and transverse rail extensions, bus stations, ferries, and A,B roads, each within their effective ranges. The outward/inward ratio within $0.3 \mathrm{~km}$ gave $\mathrm{RR}=1.70$ (1.61-1.81), and attributable cases increased to $21.3 \%$. Extension to $3.0 \mathrm{~km}$ increased this to $24.1 \%$.

\section{DISCUSSION}

These results confirm the prior hypothesis that many childhood cancers are initiated by short range exposure of the fetus or infant to exhaust fumes from ICEs. Earlier migration analyses had shown that ICE associated 1,3-butadiene was the probable agent. ${ }^{45}$ Other reported investigations of ICE proximities have mainly used case-control comparisons and their conclusions have varied, but several have produced evidence of road traffic proximities. ${ }^{11-19}$ Some regarded benzene, nitrogen oxides, or particulates as the main hazard, but chiefly on an a priori basis. None of them sought directly to identify the agent and none specifically incriminated 1,3butadiene.

This study shows effective exposures within $100 \mathrm{~m}$ of engine gas sources, tapering with increasing distance, and confirming expectations for a ground level discharge. These findings, and the separation of the components, depended crucially upon the availability of high resolution OS data on roads, railways, and railway stations. These data are presented to a precision of $1 \mathrm{~m}$ although ground accuracy (for example, for interpolations between the vertices of linear features) is less certain. However the OS specifications for its $1: 250000$ maps suggest a mean error on the ground of about $20 \mathrm{~m}$ (see appendix). This is sufficient for present purposes.

Diesel fumes were initially implicated by high birth frequencies near bus/coach stations and railways. However, this emphasis was partly attributable to the relative ease of defining sites with high levels of diesel emissions; in contrast with the ubiquity of petrol engine exhausts. Local effects from rail diesel were supported by birth concentrations around acceleration zones within $400 \mathrm{~m}$ of stations and by regional differences related to rail electrification. However, results near transverse station extensions suggested a major non-locomotive railside effect and there were no evident correspondences between rail proximities and the progressive introduction of diesel locomotives between 1960 and 1968. Combined and separate analyses of roads and railways then showed that the road effect was paramount and that the rail proximities of cancer births were largely explicable by nearby roads. However, the distinction is still incompletely resolved and it would be a mistake to regard these findings as exonerating diesel locomotives. We should probably still treat all low level ICE exhausts as hazardous.

Links were sought between seasonal cancer birth excesses and local holiday period surges of road traffic. The exposure to birth interval might thus have been estimated from a mutual offset. Surprisingly there were no such links. However, this negative finding leads to the important inference that exhaust gas inhalations must be effective after varying intervals, smoothing out seasonal exposure variations. This implies that the mother probably accumulates toxic materials over long periods, concentrating low ambient levels of carcinogen through a "biological magnification" process. Such processes have been recognised in other contexts: for example, in food chain concentrations of DDT, or the dietary toxin pathways responsible for endemic neurodegenerative disease on the island of Guam..$^{20-22}$ The possibility deserves examination here.

What proportion of all child cancers might be initiated by exhaust gas exposures? Firstly, we can suppose that exposed non-migrants suffered to the same degree as migrants; or more so if there is a postnatal component. Secondly, we can suppose that the measured proximities supply only a very crude indicator of all maternal/child exposures. More specific measures of exposure (for example, including their own cars) must be capable of explaining many more than the $24 \%$ found here; and ICE exhaust exposure can probably be regarded as the major initiating cause of these diseases in this country during these years. It was a more powerful hazard than medical radiation, which resulted in about $6 \%$ of cases, and much more powerful than any effects of exposure to non-ionising electromagnetic radiation. ${ }^{23}$

However, this may be only a part explanation and there is room for other external cofactors here, especially in relation to clinical onsets of leukaemia. Stimulated proliferation of an existing malignant clone by a viral or other infection offers a reasonable pathogenetic model for a tumour of the immune system; and this could explain the many reported occurrences of close-set space-time onset clusters.

\section{ACKNOWLEDGEMENTS}

The cancer data were supplied by the late Professor A M Stewart.

Funding: the postcoding of the cancer records was supported by the Medical Research Council and by the Three Mile Island Public Health Fund (USA).

Conflicts of interest: none declared.

The author is Emeritus Professor, University of Birmingham, UK 


\section{APPENDIX}

Digimap featurecodes and numbers of coordinates in each

\begin{tabular}{lll}
\hline Feature & Codes & Coordinates \\
\hline Bus/coach stations & (direct map reading) & 455 \\
OS bus stations & (direct map reading) & 302 \\
Railway stations & 5520 & 2531 \\
Railways & $5510,5511,5512,5513$ & 78378 \\
Motorways & 5310,5312 & 9984 \\
A class roads & $5330,5332,5333,5335$ & 146943 \\
B class roads & $5340,5342,5343,5345$ & 164227 \\
Minor roads $>4$ m wide & 5350 & 382817 \\
Minor roads $<4$ m wide & 5405 & 481880 \\
River, main, lower & 5213 & 15505 \\
Other rivers & $5211,5212,5221,5222,5230$ & 857107 \\
\hline
\end{tabular}

Map data were downloaded in DXF format and hazard lists were extracted using specially written PASCAL programs. Coordinates are specified to one metre precision but OS warns that this is not a meaningful statement of ground accuracy. OS quoted tolerances on their 1:250 000 printed maps, derived from these data, suggest maximum ground errors of 25 metres for points and vertices $(0.1 \mathrm{~mm}$ on map) and 50 metres for interpolations $(0.2 \mathrm{~mm})$. Mean errors are probably around 20 metres.

\section{REFERENCES}

1 Knox EG, Gilman EA. Hazard proximities of childhood cancers. J Epidemiol Community Health 1995;51:151-9.

2 Knox EG, Gilman EA. Migration patterns of children with cancer in Britain. $J$ Epidemiol Community Health 1998;52:716-26.

3 Knox EG. Childhood cancers, birthplaces, incinerators and landfill sites. International J Epidemiology 2000;29:391-7.

4 Knox EG. Childhood cancers and atmospheric carcinogens. J Epidemiol Community Health 2005;59:101-5.

5 Knox EG. Oil combustion and childhood cancers. J Epidemiol Community Health 2005;59:755-60.

6 National Atmospheric Emissions Inventory. Dec 2003. http:// www.naei.org.uk/mapping.

7 Dore CJ, Goodwin JWL, Watterson JD, et al. UK emissions of air pollutants 1970 to 2001, National Environmental Technology Centre http://

www.airquality.co.uk/archive/reports/cat07/naei_report_1970-2001.pdf.

8 Knox EG, Stewart AM, Kneale GW, et al. Prenatal irradiation and childhood cancer. J Soc Radiol Protection 1987;7:177-89.

9 Digimap. http://edina.ac.uk/.

10 Baker SK. Rail atlas. 7th ed. California: Oxford Publishing Company, 1992.

11 Pearson RL, Wachtel H, Ebi KL. Distance-weighted traffic density in proximity to a home is a risk factor for leukemia and other childhood cancers. J Air Waste Manag Assoc 2000;50:175-80.

12 Crosignani $\mathbf{P}$, Tittarelli A, Borgini A, et al. Childhood leukemia and road traffic: a population-based case-control study. Int J Cancer 2004;108:596-9.

13 Feychting N, Svensson D, Ahlbom A. Exposure to motor vehicle exhaust and childhood cancer. Scand J Work Environ Health 1998;24:8-11.
14 Harrison PM, Leung PL, Sommervaille L, et al. Analysis of incidence of childhood leukaemia in the West Midlands of the United Kingdom in relation to proximity to main roads and petrol stations. Occup Environ Med 1999;56:774-80

15 Savits DA, Feingold L. Association of childhood cancer with residential traffic density. Scand J Work Environ Health 1989:15:360-3.

16 Langholz B, Ebi KL, Thomas DC, et al. Traffic density and the risk of childhood leukemia in a Los Angeles case-control study. Ann Epidemiol 2002; 12:482-7.

17 Reynolds P, Elkin E, Scalf R, et al. A case-control pilot study of traffic exposures and early childhood leukemia using a geographic information

18 System. Bioelectromagnetics 2001;(suppl 5):58-68. environmental exposure to potential sources of benzene and other hydrocarbons; a case-control study. Occup Environ Med 2004;61:773-8.

19 Reynolds P, Von Behring J, Gunier RB, et al. Residential exposure to traffic in California and childhood cancer. Epidemiology 2004;15:6-12.

20 Wiener J. The Tangle. An ethnobiologist tries to solve the mystery of neurological disease on Guam. New Yorker, 2005;Apr 11.

21 Murch SJ, Cox PA, Banack SA. Mechanism for slow release of biomagnified cyanobacterial neurotoxins and neurodegenerative disease in Guam. http:// www.pns.org/cgi/10.1073/pnas.0404926101.

22 Bell EA. The discovery of BMAA, and examples of biomagnification and protein incorporation involving other nonprotein amino acids. In: Cox PA, ed. $B M A A$, excitotoxicity, neural degeneration and epidemiology (in press).

23 Draper G, Vincent T, Kroll ME, et al. Childhood cancer in relation to distance from high voltage power lines in England and Wales: a case-control study. BMJ 2005;330:1290-2. 